\title{
Proteolysis of cystatin C by cathepsin D in the breast cancer microenvironment
}

Valérie Laurent-Matha ${ }^{1 *}$, Pitter F. Huesgen ${ }^{2^{*}}$, Olivier Masson ${ }^{1 *}$, Danielle Derocq ${ }^{1}$,

Christine Prébois ${ }^{1}$, Magali Gary-Bobo ${ }^{1}$, Fabien Lecaille $^{3}$, Bertrand Rebière ${ }^{4}$, Guillaume Meurice $^{5}$, Cédric Oréar $^{5}$, Robert E. Hollingsworth ${ }^{6}$, Magnus Abrahamson ${ }^{7}$, Gilles Lalmanach ${ }^{3^{* * *}}$, Christopher M. Overall ${ }^{2}$, Emmanuelle Liaudet-Coopman ${ }^{1 * *+* * *}$.

${ }^{1}$ IRCM, Institut de Recherche en Cancérologie de Montpellier, INSERM U896, Université Montpellier1, CRLC Val d'Aurelle Paul Lamarque, Montpellier, F-34298, France. ${ }^{2}$ University of British Columbia, Centre for Blood Research, British Columbia, V6T 1Z3, Canada. ${ }^{3}$ INSERM U1100 (Pathologies Respiratoires: Protéolyse et Aérosolthérapie), Université François Rabelais, Faculté de Médecine, Tours, F37032, France. ${ }^{4}$ CRBM Centre de Recherche de Biochimie Macromoléculaire, CNRS UMR5237, Montpellier, F-34293, France. ${ }^{5}$ Functional Genomic Plateform, Institut Gustave Roussy, Villejuif, F-94805 France. ${ }^{6}$ Oncology Research, Medlmmune, Inc., Gaithersburg, MD 20878, USA. ${ }^{7}$ Dept. of Laboratory Medicine, Div. Clinical Chemistry, Lund University, University Hospital, S-221 85 Lund, Sweden.

${ }^{*}$ Authors contributed equally to the work.

${ }^{* *}$ Corresponding author: E Liaudet-Coopman, E-mail: emmanuelle.liaudetcoopman@inserm.fr

${ }^{* * *}$ Both INSERM U896 and INSERM U1100 are affiliated to the LabEx Mablmprove Tours-Montpellier

Short title: Proteolysis of cystatin C by cathepsin D 


\section{NON STANDARD ABBREVIATIONS}

Arg: arginine

BSA: Bovine serum albumin

CA-074: (L-3-trans-(Propylcarbamyl)oxirane-2-carbonyl)-L-isoleucyl-L-proline

Cath-D: cathepsin D

CM: Conditioned medium

C-terminal : carboxy-terminal

Cyst C: cystatin C

Da: Dalton

DMEM : Dulbecco's Modified Eagle Medium

DTT : dithiothréitol

E-64: N-[N-(L-3-trans-carboxyirane-2-carbonyl)-L-leucyl]-agmatine; [1-[N-[(L-3-transcarboxyoxirane-2-carbonyl)-L-leucyl]amino]-4-guanidinobutane]

EDTA: ethylenediaminetetra-acetic

EF: eluted fraction

FCS: fetal calf serum

GST: glutathione S-transferase

h: hour

$\mathrm{HCl}$ : Hydrochloric acid

HPLC: High-performance liquid chromatography

IgG: Immunoglobulin G

IP: immunoprecipitation

iTRAQ : Isotope Tags for Relative and Absolute Quantification

KDa: kiloDalton

LC-MS/MS: Liquid chromatography coupled to tandem mass spectrometry 
Luc: luciferase

MEF: mouse embryonic fibroblast

min: minute

$\mathrm{N}$-terminal : amino-terminal

Opti-MEM : Dulbecco's Modified Eagle Medium

Pepst.: Pepstatin A

Pro-cath-D: procathepsin D

SDS-PAGE: SDS-PolyAcrylamide Gel Electrophoresis

siRNA: silencing RNA

TAILS: terminal amine isotopic labelling of substrates 


\begin{abstract}
The aspartic protease cathepsin D, a poor prognostic indicator of breast cancer, is abundantly secreted as procathepsin D by human breast cancer cells and selfactivates at low $\mathrm{pH}$ in vitro, giving rise to catalytically-active cathepsin $\mathrm{D}$. Due to a lower extracellular $\mathrm{pH}$ in tumor microenvironments compared to normal tissues, cathepsin D may cleave pathophysiological substrates contributing to cancer progression. Here, we show by yeast two-hybrid and degradomics analyses that cystatin $\mathrm{C}$, the most potent natural secreted inhibitor of cysteine cathepsins, both binds to and is a substrate of extracellular procathepsin D. The amount of cystatin $C$ in the extracellular environment is reduced in the secretome of mouse embryonic fibroblasts stably transfected with human cathepsin D. Cathepsin D extensively cleaved cystatin $\mathrm{C}$ in vitro at low $\mathrm{pH}$. Cathepsin $\mathrm{D}$ secreted by breast cancer cells also processed cystatin $\mathrm{C}$ at the pericellular $\mathrm{pH}$ of tumors so enhancing extracellular proteolytic activity of cysteine cathepsins. Thus, tumor derived cathepsin D assists breast cancer progression by reducing cystatin C activity, which in turn enhances cysteine cathepsin proteolytic activity, revealing a new link between protease classes in the protease web.
\end{abstract}

Key words: cancer, cathepsins, cystatins, proteolysis, protease web 


\section{INTRODUCTION}

Human cathepsin D is a ubiquitous, lysosomal, aspartic endoproteinase that is proteolytically active at low $\mathrm{pH}$. Cathepsin $\mathrm{D}$ is overproduced and abundantly secreted by human epithelial breast cancer cells $(1,2)$ with expression levels in breast cancer correlating with poor prognosis $(3,4)$. Cathepsin D affects both cancer and stromal cells in the tumor microenvironment by increasing the proliferation of cancer cells $(1,5,6)$, stimulating fibroblast outgrowth $(7,8)$, angiogenesis $(5,9)$, and metastasis (10). However, little is known of the molecular mechanisms involved or its substrates in these processes.

Human cathepsin $\mathrm{D}$ is synthesized as a $52-\mathrm{kDa}$ precursor that is converted in the endosomes to an active, 48-kDa single-chain intermediate, and then to the fully active mature protease in the lysosomes. Mature human cathepsin D is composed of a 34-kDa heavy chain and a $14-\mathrm{kDa}$ light chain. Its catalytic site includes two critical aspartic residues, residues 33 on the $14-\mathrm{kDa}$ chain and 231 on the $34-\mathrm{kDa}$ chain. The over-production of cathepsin D by breast cancer cells leads to hypersecretion of the $52-\mathrm{kDa}$ procathepsin $\mathrm{D}$ into the extracellular environment $(1,2)$. Purified $52-\mathrm{kDa}$ procathepsin D auto-activates in acidic conditions giving rise to a catalytically active $51-\mathrm{kDa}$ pseudo-cathepsin $\mathrm{D}$, which retains the 18 residues $(27-44)$ of the prosegment (11). While the extracellular environment is more acidic in tumors than in the corresponding normal tissues (12-14), the question is whether it is sufficiently acidic for procathepsin D to cleave its pathophysiological substrates. If so, the identification of these substrates will be important for the mechanistic understanding of the role of this protease in cancer. 
We show that procathepsin D secreted by breast cancer cells binds to cystatin $\mathrm{C}$ and specifically hydrolyses this cysteine protease (family $\mathrm{C} 1$ ) inhibitor. Cysteine cathepsins promote the proliferation, invasion, and metastasis of cancer cells $(15,16)$ suggesting a new unexplored link in the protease web $(17,18)$. Using a degradomics approach known as terminal amine isotopic labelling of substrates (TAILS) $(19,20)$, we found that the amount of cystatin $\mathrm{C}$ in the extracellular environment is reduced in a cathepsin D-dependent manner in the secretome of mouse embryonic fibroblasts (MEFs) derived from cathepsin D knock-out mice stably transfected with human cathepsin $\mathrm{D}$ compared to cathepsin $\mathrm{D}^{-/ 2}$ MEFs. In particular, we show that procathepsin $D$ secreted by breast cancer cells contributes to the protease web in the acidic tumor microenvironment by specific cleavages in cystatin $\mathrm{C}$, thereby increasing cysteine cathepsin proteolytic activity. 


\section{MATERIALS AND METHODS}

\section{Yeast two-hybrid assay}

Human cath-D was fused with the LexA DNA-binding domain of the pMW101 vector. A cDNA library derived from normal breast tissue was cloned into the galactosidaseinducible pYESTrp2 vector (Invitrogen) containing a B42 activating domain. The yeast two-hybrid screen was performed as described previously (8).

\section{Plasmids}

Human pcDNA3.1(-)cathepsin D expression plasmid has previously been described (8). The full-length human cystatin $\mathrm{C}$ was sub-cloned from the pUC18 cystatin C plasmid into the HindIII and EcoR1 sites of the pcDNA3.1(+) vector (Invitrogen) to make pcDNA3.1(+)cystatin C. For GST pull-down, pGEX-4T-2cystatin C was generated by inserting PCR-amplified cDNA encoding human cystatin C (1-146) from pcDNA3.1(+)cystatin C into pGEX-4T-2 that had been digested by EcoRI and Xhol.

\section{GST pull-down assay}

$\left[{ }^{35}\right.$ S $]$ methionine-labeled procathepsin $\mathrm{D}$ was obtained by transcription and translation using the $\mathrm{TNT}^{\mathrm{T} 7}$-coupled reticulocyte lysate system (Promega). GST and GSTcystatin C fusion proteins were produced in Escherichia coli B strain BL21 by incubation with isopropyl-1-thio- $\beta$-D-galactopyranoside $(1 \mathrm{mM})$ for $3 \mathrm{~h}$ at $37^{\circ} \mathrm{C}$. The GST fusion proteins were purified on glutathione-Sepharose beads (Amersham Biosciences). For pull-down assays, $20 \mu \mathrm{l}$ bed volume of glutathione-Sepharose beads with immobilized GST fusion proteins were incubated overnight at $4^{\circ} \mathrm{C}$ with $\left[{ }^{35}\right.$ S $]$ methionine-labeled proteins in $500 \mu \mathrm{PDB}$ buffer $(20 \mathrm{mM}$ HEPES-KOH $(\mathrm{pH} 7.9)$, 
$10 \%$ glycerol, $100 \mathrm{mM} \mathrm{KCl}, 5 \mathrm{mM} \mathrm{MgCl} 2,0.2 \mathrm{mM}$ EDTA, $1 \mathrm{mM}$ DTT, $0.2 \mathrm{mM}$ phenylmethylsulfonylfluoride) containing $15 \mathrm{mg} / \mathrm{ml} \mathrm{BSA}$ and $0.1 \%$ Tween 20 . The beads were washed four times with $500 \mu$ PDB buffer, and the eluted proteins were resolved by $15 \%$ SDS-PAGE, stained with Coomassie blue, and exposed to X-ray film.

\section{Secretome preparation}

Cathepsin $\mathrm{D}^{-/}$immortalized MEFs stably transfected with empty vector (CD55-/SV40) or the cath-D expression vector encoding human pre-procathepsin D (CD55-/cath-D) were prepared as previously described (7). MEF cells (6 T175 flasks per condition) grown to $80 \%$ confluence were washed extensively with phenol red-free, serum-free medium to remove serum proteins and grown overnight in phenol redfree, serum-free medium. Samples of conditioned medium were immediately treated with protease inhibitors ( $1 \mathrm{mM}$ EDTA, protease inhibitor cocktail (Complete; Roche Applied Science)), clarified by centrifugation (5 min, $500 \mathrm{~g} ; 30 \mathrm{~min}, 8,000 \mathrm{~g}$ ) and filtered $(0.45 \mu \mathrm{M})$. Conditioned medium proteins in $50 \mathrm{mM}$ Hepes, $\mathrm{pH} 7.5$ were then concentrated to $2 \mathrm{mg} / \mathrm{ml}$ by passage through Amicon filters ( $3 \mathrm{kDa}$ cut-off, Millipore).

\section{Enrichment and mass spectrometric analysis of protein $\mathrm{N}$-termini}

Protein N-terminal peptides were enriched using Terminal Amine Isotope Labeling of Substrates (TAILS) as described (19) using the option for isotopic labeling of proteins with ITRAQ reagents. Peptides were pre-fractionated by strong cation exchange chromatography and analysed by LC-MS/MS (QSTAR XL, Applied Biosystems). Peptides were identified at the $95 \%$ confidence level from the human UniProtKB/Swissprot protein database (release date) using two search engines, 
MASCOT v2.3 (Matrix Science) and X!TANDEM (21), in conjunction with PeptideProphet (19) as implemented in the Trans Proteomic Pipeline v4.3. Search parameters were: Semi-ArgC peptides with up to two missed cleavages, $0.4 \mathrm{Da}$ precursor ion mass tolerance, $0.4 \mathrm{Da}$ fragment ion mass tolerance, carboxyamidomethylation of cysteine residues $(+57.02 \mathrm{Da})$ and iTRAQ-labeling of lysine e-amines $(+144.10 \mathrm{Da})$ as fixed modifications, and peptide $\mathrm{N}$-terminal iTRAQ labelling (+144.10 Da), peptide $\mathrm{N}$-terminal acetylation (+42.01 Da) and Met oxidation (+15.99 Da) as variable modification. Results from both searches were combined using an in-house software script (22), requiring peptides to have an Arg at their Cterminus and showing an iTRAQ reporter ion intensity of $>30$ in at least one of the compared channels. N-terminal peptides with significant changes between two conditions were determined by calculation the log2 of the intensity rations, correction for the mean of all ratios, and application of a 3-fold change cut-off (mean-corrected $\log 2>1.58$ or $<-1.58)$. The data associated with this manuscript may be downloaded from the ProteomeCommons.org Tranche network using the following hash:

yYqDvOHCujSd0Ng/7rrjUz9E4f4ru5BO1CMEIAKbaYTnVucBssF7vP9jBu8PhzZktFjT OwzBpttpDPOGKsl4j+KdRTgAAAAAAAADiw==. The passcode for downloading the data is: CDsecretomeTAILS.

\section{SiRNA transfection}

Duplexes of 21-nucleotide human cathepsin D (target sequence AAGCUGGUGGACCAGAACAU (8)) or firefly luciferase (Luc) siRNA (target sequence AACGUACGCGGAAUACUUCGA) were synthesized by MWG Biotech S.A. MCF-7 cells were transiently transfected with $5 \mu \mathrm{g}$ human cathepsin D or Luc siRNAs using Oligofectamine (Invitrogen). $48 \mathrm{~h}$ post-transfection, the culture medium 
was then changed and conditioned medium was prepared by incubating the siRNAtransfected cells in FCS-free DMEM buffered with $50 \mathrm{mM}$ Hepes $(\mathrm{pH} 7)$ for $24 \mathrm{~h}$.

Transfection, immunoprecipitation, immunoblotting and purification of cathepsin D and cystatin C

Cells were cultured in DMEM (Invitrogen) supplemented with 10\% fetal calf serum (FCS). COS cells were co-transfected with $10 \mu \mathrm{g}$ pcDNA3.1(+) cystatin C and $10 \mu \mathrm{g}$ pcDNA3.1(-)cathepsin D vector. Cells were transiently transfected using Lipofectamine and Opti-MEM (Gibco-BRL). The conditioned media collected two days post-transfection were incubated overnight at $4^{\circ} \mathrm{C}$ with: $3 \mu \mathrm{g}$ anti-cathepsin $\mathrm{D}$ M1G8 monoclonal antibody (8), or MOPC21 control monoclonal antibody (Abcam), or $3 \mu \mathrm{g}$ anti-cystatin $\mathrm{C}$ rabbit polyclonal antibody (DAKO), or control rabbit IgG (R\&D Systems), and then with $25 \mu \mathrm{l}$ of $10 \%$ protein A-Sepharose, for $2 \mathrm{~h}$ at $4^{\circ} \mathrm{C}$ on a shaker. The Sepharose beads were washed 4 times with DMEM, boiled for $3 \mathrm{~min}$ in SDS sample buffer, and analysed by SDS-PAGE and immunoblotting using the antihuman cathepsin $\mathrm{D}$ monoclonal antibody (BD Biosciences) or anti-cystatin $\mathrm{C}$ rabbit polyclonal antibody as previously described $(7,8)$. Procathepsin D was purified from medium in which NIH-3T3 cells stably transfected with human cathepsin D or MCF-7 breast cancer cells had been incubated for $24 \mathrm{~h}$ in DMEM without FCS. These conditioned media were then passed through an anti-cathepsin D M1G8-coupled agarose column. The column was washed with $20 \mathrm{ml}$ of $0.5 \mathrm{M}$ phosphate buffer $(\mathrm{pH}$ 7), $0.15 \mathrm{M} \mathrm{NaCl}, 0.01 \%$ Tween $20,80.5 \mathrm{mM} \beta$-glycerophosphate containing protease inhibitor cocktail (Complete; Roche Applied Science), and then eluted with a $20 \mathrm{mM}$ lysine solution $(\mathrm{pH} \mathrm{11)}$. Cystatin $\mathrm{C}$ eluted together with procathepsin $\mathrm{D}$ was analyzed by SDS-PAGE and immunoblotting. 


\section{Cleavage of cystatin $C$ by cathepsin $D$ in vitro}

Recombinant procathepsin D $(2 \mu \mathrm{g})$ (R\&D Systems) was auto-activated for $1 \mathrm{~h}$ at $37^{\circ} \mathrm{C}$ in $50 \mu \mathrm{l}$ of $0.1 \mathrm{M} \mathrm{Na}$-acetate buffer $(\mathrm{pH} 3.5), 0.2 \mathrm{M} \mathrm{NaCl}$. An aliquot $(15 \mu \mathrm{g})$ of recombinant cystatin C (Abcam) was incubated with $25 \mu \mathrm{l}$ cathepsin D $(1 \mu \mathrm{g})$ overnight at $37^{\circ} \mathrm{C}$ at $\mathrm{pH} 3.5$. The cathepsin $\mathrm{D}$ had been auto-activated in $0.1 \mathrm{M} \mathrm{Na}$ acetate buffer ( $\mathrm{pH}$ 3.5) $0.2 \mathrm{M} \mathrm{NaCl}$, with or without pepstatin A (2 $\mu \mathrm{M})$ (Sigma) in a volume of $200 \mu \mathrm{l}$. Cleaved peptides were resolved by reverse-phase HPLC on a C8 column eluted with an acetonitrile gradient in $0.075 \%$ trifluoroacetic acid, and $\mathrm{NH}_{2}-$ terminal sequence analysis performed by automatic Edman degradation on a Procise sequencer (492 Protein Sequencer, Applied Biosystem). Phosphatidylcholine (Sigma; $0.12 \mathrm{mM}$ ) and cardiolipin (Sigma; $0.05 \mathrm{mM}$ ) were added in the reaction mixture for cleavage performed at higher $\mathrm{pH}$ according to (23).

\section{Degradation of extracellular cystatin C by secreted procathepsin D}

Conditioned medium from MCF-7 cells was obtained by incubating cells for $24 \mathrm{~h}$ in DMEM without sodium bicarbonate buffered with $50 \mathrm{mM}$ Hepes buffer $(\mathrm{pH} 7)$ in absence of FCS. The $24 \mathrm{~h}$ conditioned medium was then incubated, with or without pepstatin $\mathrm{A}(50 \mu \mathrm{M})$, at $37^{\circ} \mathrm{C}$ at $\mathrm{pH} 3.5$ by acidification with $1 \mathrm{~N} \mathrm{HCl}$, for up to $3 \mathrm{~h}$. In other experiments, the $24 \mathrm{~h}$ conditioned medium was incubated, with or without pepstatin $\mathrm{A}(50 \mu \mathrm{M})$, at $37^{\circ} \mathrm{C}$ for $1 \mathrm{~h}$ at different $\mathrm{pH}$ values using Britton-Robinson buffer. The proteins in this treated medium $(20 \mu \mathrm{l})$ were separated by $17 \%$ SDSPAGE and immunoblotted for cystatin $C$ using anti-cystatin $C$ rabbit polyclonal antibody (DAKO). 


\section{Quantification of cysteine cathepsin activity}

Conditioned media of MCF-7 cells silenced or not for cathepsin D and incubated at $\mathrm{pH} 3.5$ for $10 \mathrm{~min}$, or at $\mathrm{pH} 5.6$ for 1 or $2 \mathrm{~h}$ were incubated in $100 \mathrm{mM}$ sodium acetate buffer (pH 5.5) containing 4 mM DTT, 2 mM EDTA in the presence of Z-Phe-ArgAMC $(40 \mu \mathrm{M})$, and cysteine cathepsin proteolytic activity was monitored continuously for $120 \mathrm{~min}$ at $\lambda \mathrm{exc}=350 \mathrm{~nm}$ and $\lambda \mathrm{em}=460 \mathrm{~nm}$ (Gemini spectrofluorimeter, Molecular Devices, France). Controls were performed in the presence of the broad-spectrum cysteine cathepsin inhibitor, E-64 $(10 \mu \mathrm{M})$, or the cathepsin B inhibitor, CA-074 (4 $\mu \mathrm{M})$.

\section{Immunoblotting of cysteine cathepsins}

The goat anti-human cathepsin S was obtained from R\&D Systems (Lille, France). Other primary polyclonal antibodies were raised in rabbits: anti-human cathepsin B (Calbiochem, VWR International S.A.S., France), anti-human cathepsin L (Calbiochem), anti-human cathepsin H (Fitzgerald, Concord, USA). Goat anti-rabbit and rabbit anti-goat IgG-peroxidase conjugates were supplied by Sigma-Aldrich. Human cathepsins used as control were supplied by Calbiochem. Sample (30 $\mu \mathrm{g})$ from culture medium of MCF-7 cells conditioned for $24 \mathrm{~h}$ without FCS and $100 \mathrm{X}$ concentrated by passage through Amicon filters to $2 \mu \mathrm{g} / \mathrm{ml}$ was diluted in Laemmli buffer under reducing conditions, boiled for $5 \mathrm{~min}$, separated by SDS-PAGE on 15\% gels (prestained molecular masses: Precision Plus Protein Standards, BioRad) and electroblotted onto nitrocellulose membranes. These membranes were incubated with the primary antibody $(1 \mu \mathrm{g} / \mathrm{ml}$, in PBS, $0.1 \%$ Tween, $5 \%$ dried milk for $1 \mathrm{~h}$ at room temperature), then with the secondary IgG-peroxidase conjugate for $1 \mathrm{~h}$ at 
room temperature. Proteins were detected by chemiluminescence (ECL Plus Western Blotting Detection system, Amersham Biosciences, Buckinghamshire, UK).

\section{RESULTS}

\section{Cystatin C binds to procathepsin D secreted by breast cancer cells at neutral} $\mathrm{pH}$

We performed a yeast two-hybrid screening using a LexA DNA-binding domain fused to the $48-\mathrm{kDa}$ intermediate human cathepsin $\mathrm{D}$ as bait, and a cDNA library isolated from normal human breast tissue to identify new molecules that interact with cathepsin D. The clone we isolated was $100 \%$ identical to amino acids $39-146$ of cystatin C (Fig. 1A). We then verified this interaction by GST pull-down experiments with full-length human cystatin C fused to GST (GST-cyst C) (Fig. 1B, panel a). Procathepsin D was bound to GST-cyst C (Fig. 1B, panel b), indicating that cystatin C interacts directly with procathepsin D.

Next we then co-transfected COS cells with cystatin $C$ and procathepsin $D$ expression vectors to determine whether procathepsin D interacted with cystatin C extracellularly. Upon incubation with an anti-cystatin C antibody, analysis of the conditioned medium from these cells showed that secreted $52-k D a$ procathepsin $D$ was immunoprecipitated with 14-kDa cystatin C (Fig. 1C, panel a). Reciprocally, incubation of the conditioned medium with anti-cathepsin D antibody showed that secreted cystatin C was immunoprecipitated along with procathepsin D (Fig. 1C, panel b). Thus, the procathepsin D and cystatin C co-transfected in COS cells interacted in the extracellular environment at neutral $\mathrm{pH}$.

We confirmed this extracellular interaction between procathepsin $D$ and cystatin C by studying the interaction of procathepsin $\mathrm{D}$ with the cystatin $\mathrm{C}$ secreted by $\mathrm{NIH}$ - 
3T3 fibroblasts stably transfected with cathepsin $\mathrm{D}$ at neutral $\mathrm{pH}$. Immunoaffinity purification of procathepsin $D$ with an anti-cathepsin $D$ antibody revealed that cystatin C copurified with procathepsin D (Fig. 1D, panel a). This indicates that secreted cystatin C interacts with the procathepsin D synthesized by stably-transfected $\mathrm{NIH}$ 3T3 fibroblasts at neutral $\mathrm{pH}$.

We screened cystatin $C$ secretion in a variety of breast cancer cell lines to verify the extracellular interaction between procathepsin D and cystatin C (Fig. S1). Cathepsin $D$ is known to be over-produced and hypersecreted by breast cancer cells $(1,2)$, and our survey revealed that all the breast cancer cell lines tested, except the BT20 cell line, secreted cystatin C (Fig. 1D, panel c). Lastly, since breast cancer cells synthesize and secrete procathepsin D and cystatin $C$, we investigated their interaction in the conditioned medium from MCF-7 breast cancer cells at neutral $\mathrm{pH}$. Again, cystatin $C$ was purified together with procathepsin D (Fig. 1D, panel b). We conclude that cystatin $C$ and procathepsin D interact in secretome of MCF-7 breast cancer cells. We have thus shown that procathepsin $D$ interacts directly with cystatin $\mathrm{C}$ in the extracellular space of breast cancer cells at neutral $\mathrm{pH}$.

\section{Identification of the extracellular proteins affected by a cathepsin D deficiency}

We analysed the secreted proteome harvested from cathepsin $D^{-/-}$MEFs stably transfected with empty vector (CD55-/-SV40) or human cathepsin D (CD55-/- cath-D) vector by TAILS at neutral $\mathrm{pH}$ to determine the impact of cathepsin $\mathrm{D}$ on extracellular protein processing. We identified 746 unique $\mathrm{N}$-terminal peptides from 569 unique proteins, and quantified 710 of the $\mathrm{N}$-termini from 542 proteins (Fig. 2A). A threefold change was used as cut-off to determine $\mathrm{N}$-termini substantially affected by cathepsin D activity, as in earlier TAILS studies $(19,24)$. Based on this criterion, 22 
neo- $\mathrm{N}$ termini were more abundant in cells producing cathepsin $\mathrm{D}$ than in cells transfected with the empty vector, while 48 mature protein $\mathrm{N}$ termini were reduced in abundance in the secretome of cathepsin D-transfected cells, indicating cleavage and loss of the peptide from cleaved or degraded protein (Table S1).

Notably,the $\mathrm{N}$-terminus of mature cystatin $\mathrm{C}$ was 7 -fold less abundant in the secretome of cathepsin D transfected cells (CD55-/- cath-D) compared to that of cathepsin D deficient cells (CD55-/-SV40) (Table S1). Furthermore, analysis of the transcriptome of C55-/-SV40 and C55-/-cath-D cells showed that the reduced cystatin C protein in the C55-/-cath-D secretome was not due to down-regulation of cystatin C gene expression in the presence of cathepsin D (Fig. 2B, Table S2). Thus, proteomics analysis shows that the amount of cystatin $C$ in the extracellular environment is reduced in a cathepsin D-dependent manner.

\section{Cleavage of cystatin $C$ by human procathepsin $D$ in vitro}

We investigated the capacity of cathepsin $D$ to cleave cystatin $C$ in vitro at low $\mathrm{pH}$. Recombinant 52-kDa human procathepsin $\mathrm{D}$ was auto-activated to $51-\mathrm{kDa}$ proteolytically active enzyme (Fig. 3, panel a) and then incubated at $\mathrm{pH} 3.5$ with recombinant human cystatin $\mathrm{C}$. This resulted in extensive hydrolysis of cystatin $\mathrm{C}$ at 10 major and 3 minor cleavage sites (Fig. 3, panel b). The 10 major sites overlapped with the 4 cleavage sites described previously for $34+14-k D a$ mature human cathepsin D (25). Pepstatin A, an inhibitor of aspartic proteases, inhibited the autoactivation of recombinant procathepsin D (Fig. 3, panel a), and the cleavage of cystatin $C$ (data not shown). Thus, procathepsin $D$ degrades cystatin $C$ in an acidic environment in vitro. 


\section{Degradation of cystatin $C$ by cathepsin $D$ secreted by breast cancer cells at acidic pH}

Since the extracellular environment of tumors is acidic, we examined the capacity of procathepsin D interacting extracellularly with cystatin $C$ to degrade it in the extracellular medium of breast cancer cells at low pH (Fig. 4). The 52-kDa procathepsin D secreted in the conditioned medium of MCF-7 breast cancer cells was auto-activated into the $51-\mathrm{kDa}$ proteolytically-active form at low pH (Fig. 4A, panel a), as was the recombinant purified procathepsin D (Fig. 3, panel a). Cystatin C was hydrolysed in a time-dependent manner in the conditioned medium of MCF-7 breast cancer cells (Fig. 4A, panel b). Pepstatin A blocked cystatin C degradation, confirming the involvement of secreted aspartic protease proteolytic activity (Fig. 4A, panel b).

We then assessed the capacity of procathepsin $D$ to hydrolyse cystatin $C$ at the extracellular pH 5.5 to 6.8 , found within tumors (Fig. 4B, panel a). The cystatin C secreted into the conditioned medium of MCF-7 cells was significantly degraded in a pH-dependent manner from $\mathrm{pH} 3.5$ to $\mathrm{pH} 6.8$ (Fig. 4B, panel b). Hydrolysis of recombinant cystatin $\mathrm{C}$ also occurred with recombinant cathepsin $\mathrm{D}$ for acidic $\mathrm{pH}$ (3.6 to 6.2) (Fig. S1). Lastly, we determined whether procathepsin $D$ is the secreted aspartic protease responsible for the extracellular breakdown of cystatin $\mathrm{C}$. We silenced cathepsin D expression in MCF-7 cells by RNA interference such that no extracellular procathepsin D was produced (Fig. 4C, panels a and c). The silencing of cathepsin D synthesis led to decreased cystatin $\mathrm{C}$ degradation at pH 3.5 (Fig. 4C, panel b, bottom) in a time-dependent manner compared to Luc silencing (Fig. 4C, panel b, top) Similar results were obtained at pH 5.6 (Fig. 4C, panel d), confirming that procathepsin $D$ is the secreted aspartic protease responsible for cystatin $C$ 
hydrolysis under acidic conditions. Our findings therefore strongly suggest that the procathepsin $\mathrm{D}$ secreted by breast cancer cells breaks-down cystatin $\mathrm{C}$ in the acidic breast tumor micro-environment.

\section{Cystatin $\mathrm{C}$ degradation by procathepsin $\mathrm{D}$ led to increased proteolytic activity of extracellular cysteine cathepsins in breast cancer cells}

Since cystatin $\mathrm{C}$ is an extremely potent extracellular inhibitor of cysteine cathepsins, we investigated the effect of the extracellular hydrolysis of cystatin $C$ by procathepsin D on the proteolytic activity of the extracellular cysteine cathepsins (Fig. 5). We silenced cathepsin D synthesis in MCF-7 cells, which decreased the amounts of secreted procathepsin D (Fig. 5, panel a), and analysed cystatin C levels (Fig. 5, panel b), and cysteine cathepsin proteolytic activity (Fig. 5, panel c) in the extracellular medium at acidic $\mathrm{pH}$. The cystatin $\mathrm{C}$ in the conditioned medium of procathepsin D-secreting Luc-silenced cells was destroyed at pH 3.5 (Fig. 5, panel b, lane 1). As a consequence, there was an overall extracellular proteolytic activity of cysteine cathepsins (Fig 5, panel c, lane 1). The cystatin $C$ in the conditioned medium of cathepsin D-silenced cells was not degraded at pH 3.5 (Fig. 5, panel b, lane 3), and the extracellular cysteine cathepsin proteolytic activity of these cells was significantly lower by 3-fold (Fig. 5, panel c, lane 3) than that of Luc-transfected cells (Fig. 5, panel c, lane 1). In the presence of pepstatin A, the break-down of cystatin C in the conditioned medium was abolished (Fig. 5, panel b, lanes 2 and 4), and the extracellular cysteine cathepsin proteolytic activity of these cells was significantly lower (Fig 5, panel c, lanes 2 and 4), than that of Luc-transfected cells (Fig. 5, panel c, lane 1) (active cathepsins $\sim 40 \mathrm{nM}$ as determined by E-64 titration). 
In order to validate the functional relevance of this pathway at a $\mathrm{pH}$ that mimics the tumor microenvironment, we confirmed that extracellular hydrolysis of cystatin C at $\mathrm{pH} 5.6$ in the extracellular medium of MCF-7 cells (Fig. 6, panel a) led to a significant increase of extracellular cysteine cathepsin proteolytic activity (Fig. 6, panel b). Among the different cysteine cathepsins detected in the conditioned medium of MCF-7 cells, we observed mainly mature cathepsin B (both single-chain and double-chain forms) whereas aminopeptidase cathepsin $\mathrm{H}$, and cathepsins $\mathrm{L}, \mathrm{S}$ and $\mathrm{K}$ were predominantly detected under their inactive pro-form (Figure 6, panel c). CA-074 blocked $\sim 60 \%$ of the proteolytic activity towards Z-Phe-Arg-AMC, indicating that the majority of this activity was due to cathepsin B (data not shown). We therefore conclude that secreted cathepsin $D$ degrades cystatin $C$ in an acidic environment, leading to increased proteolytic activity of extracellular cysteine cathepsins, such as cathepsin B in particular (Fig. 7).

\section{DISCUSSION}

We show that cystatin $C$ is both bound to procathepsin $D$ secreted by breast cancer cells and is a substrate of the enzyme in the extracellular environment at a pH not normally associated with cathepsin D activity. Cystatin C is the most potent extracellular endogenous inhibitor of the cysteine cathepsins (15) inhibiting the growth and metastasis of many tumors $(16,26-28)$. Several studies have suggested the therapeutic use of cystatin $C$ and cysteine cathepsin inhibitors $(26,29-31)$. Cysteine cathepsins, such as cathepsin B and cathepsin L, are frequently missregulated in human cancers, and have been implicated in angiogenesis, proliferation, apoptosis, invasion and metastasis $(15,32)$. Cysteine cathepsins are secreted into the extracellular milieu during cancer progression, where they take part in a vast 
multidimensional network of proteolytic interactions involving metalloproteases and serine proteases, rather than simply functioning individually $(17,33)$. The complexity of the proteolytic activation cascade is enhanced by the presence of endogenous inhibitors specific for each class of proteases $(16,17)$. Here, we have demonstrated that the procathepsin D secreted by breast cancer cells interacts extracellularly with cystatin $\mathrm{C}$ in secretome at neutral $\mathrm{pH}$.

Secreted procathepsin $D$ has been previously described to act as an extracellular binding protein in breast cancer, for example the low-density lipoprotein receptor-related protein-1 (LRP1) is a novel cathepsin D receptor on fibroblasts (8, 34). Moreover, interaction of secreted prosaponin and procathepsin D also occurred in the breast cancer cell culture medium (35). Our TAILS experiments performed with the secretomes of cath- $\mathrm{D}^{-/}$MEFs stably transfected with human cathepsin $\mathrm{D}$ or an empty vector showed that the amount of mature cystatin $C$ in the extracellular environment was reduced in a cathepsin D-dependent manner, suggesting that cystatin $\mathrm{C}$ is a physiological substrate for cathepsin D. Earlier proteomic studies have shown that cystatin $C$ is also a substrate of matrix metalloproteinase 2 (MMP-2), being specifically inactivated upon one cleavage, so highlighting the complexity of the proteolytic cascades that are operating in the tumor microenvironment (36).

We have now shown that procathepsin $D$ extensively cleaves cystatin $C$ in an acidic environment in vitro. The main peptide bonds cleaved by cathepsin $D$ at low $\mathrm{pH}$ are Phe-Phe, Leu-Tyr, Tyr-Leu, and Phe-Tyr (37), which agrees well with the cleavage sites identified in the present study. Notably, the sensitivity of the proteomics approach used meant that other cleavage sites were also detected. Previous studies have shown that mature $34+14-k D a$ human cathepsin $\mathrm{D}$ inactivates in vitro at acidic $\mathrm{pH}$ different members of the cystatin family, such as stefin $\mathrm{A}$, stefin $\mathrm{B}$ 
and cystatin $C(25,38)$. It was described that $34+14-k D a$ human cathepsin $D$ cleaves human cystatin C into five fragments in vitro (25), but this cleavage has never been previously demonstrated to occur ex cellulo. The procathepsin D cleavage sites we identified overlap those previously reported in other systems (25). Our findings indicate that the break-down of cystatin $C$ by procathepsin $D$ also occurs in the conditioned medium of MCF-7 breast cancer cells in an acidic environment ( $\mathrm{pH} 5.5$ to 6.8), very like that frequently found in tumors due to the production of excess acid in hypoxic cells $(12,13,39)$. More recently, it was shown that cystatin $\mathrm{C}$ is a proteolytic target of cathepsin $\mathrm{D}$ in the commitment of hematopoietic stem cells to dendritic cells, indicating the relevance of this mechanism in other biological processes (40).

In the present study, we describe an increase in the proteolytic activity of the cysteine cathepsins in the acidic conditioned medium of MCF-7 breast cancer cells that paralleled the hydrolysis of cystatin $\mathrm{C}$ by procathepsin D. Among the different cysteine cathepsins detected in the conditioned medium of MCF-7 cells, we observed mainly mature proteolytically active cathepsin B whereas aminopeptidase cathepsin $\mathrm{H}$ and cathepsins $\mathrm{L}, \mathrm{S}$ and $\mathrm{K}$ were detected as proenzymes. It has been suggested that secreted procathepsin D directly activates the secreted procathepsin $B$ in an acidic environment, converting it into its mature active form (41). In this report, we confirmed that cathepsin B was well found mainly in mature form. Moreover, recent studies have indicated that the cysteine cathepsin-dependent invasiveness of tumors is linked to their proteolytic activity, and is enhanced in an acidic micro-environment (42-44). Our present findings strongly suggest that the procathepsin D secreted by breast cancer cells is part of the protease web of the tumor acidic micro-environment, destroying cystatin $\mathrm{C}$ and so increasing cysteine cathepsin proteolytic activity, such as cathepsin B in particular. 
This novel influence of secreted procathepsin $D$ on the steady-state concentration of cystatin C may be crucial for tumor progression and metastasis. Elucidating the networks of enzymatic activities that contribute to overall proteolysis during carcinogenesis may identify rate-limiting steps or pathways that could be targeted by anti-cancer treatment.

\section{ACKNOWLEDGEMENTS}

This work was supported by the 'Institut National de la Santé et de la Recherche Médicale', University of Montpellier I, 'ANR Jeunes Chercheuses, Jeunes Chercheurs' which provided a fellowship for Valérie Laurent-Matha and the CHEMORES consortium (EU FP6; grant number: LSHC-CT-2007-037665) and by a Canadian Institutes of Health Research grant (CMO) and an Infrastructure Grant from the Michael Smith Research Foundation (University of British Columbia Centre for Blood Research) and by the British Columbia Proteomics Network; C.M.O. is a Canada Research Chair in Metalloproteinase Proteomics and Systems Biology. We thank Alix Joulin-Giet (Inserm U1100, Université François Rabelais, Tours, France) for western blot analysis of cysteine cathepsins. We thank Dr Vladimir Lazar (Head of genomic core facilities at Institut Gustave Roussy, France) and the CHEMORES consortium for transcriptomic experiments. We thank Simon Thezenas (CRLC Val D’Aurelle Paul Lamarque, Montpellier, France) for statistical analysis, and Dr Owen Parkes (Romagné, France) for checking the English text. 


\section{REFERENCES}

1. Vignon, F., Capony, F., Chambon, M., Freiss, G., Garcia, M., and Rochefort, H. (1986) Autocrine growth stimulation of the MCF 7 breast cancer cells by the estrogen-regulated $52 \mathrm{~K}$ protein. Endocrinology 118, 1537-1545

2. Capony, F., Rougeot, C., Montcourrier, P., Cavailles, V., Salazar, G., and Rochefort, H. (1989) Increased secretion, altered processing, and glycosylation of pro-cathepsin D in human mammary cancer cells. Cancer Res 49, 3904-3909

3. Foekens, J. A., Look, M. P., Bolt-de Vries, J., Meijer-van Gelder, M. E., van Putten, W. L., and Klijn, J. G. (1999) Cathepsin-D in primary breast cancer: prognostic evaluation involving 2810 patients. Br J Cancer 79, 300-307

4. Ferrandina, G., Scambia, G., Bardelli, F., Benedetti Panici, P., Mancuso, S., and Messori, A. (1997) Relationship between cathepsin-D content and disease-free survival in node-negative breast cancer patients: a meta-analysis. Br J Cancer 76, 661-666

5. Berchem, G., Glondu, M., Gleizes, M., Brouillet, J. P., Vignon, F., Garcia, M., and Liaudet-Coopman, E. (2002) Cathepsin-D affects multiple tumor progression steps in vivo: proliferation, angiogenesis and apoptosis. Oncogene 21, 5951-5955

6. Glondu, M., Coopman, P., Laurent-Matha, V., Garcia, M., Rochefort, H., and Liaudet-Coopman, E. (2001) A mutated cathepsin-D devoid of its catalytic activity stimulates the growth of cancer cells. Oncogene 20, 6920-6929

7. Laurent-Matha, V., Maruani-Herrmann, S., Prebois, C., Beaujouin, M., Glondu, M., Noel, A., Alvarez-Gonzalez, M. L., Blacher, S., Coopman, P., Baghdiguian, S., Gilles, C., Loncarek, J., Freiss, G., Vignon, F., and Liaudet-Coopman, E. 
(2005) Catalytically inactive human cathepsin D triggers fibroblast invasive growth. J Cell Biol 168, 489-499

8. Beaujouin, M., Prebois, C., Derocq, D., Laurent-Matha, V., Masson, O., Pattingre, S., Coopman, P., Bettache, N., Grossfield, J., Hollingsworth, R. E., Zhang, H., Yao, Z., Hyman, B. T., van der Geer, P., Smith, G. K., and LiaudetCoopman, E. (2010) Pro-cathepsin D interacts with the extracellular domain of the beta chain of LRP1 and promotes LRP1-dependent fibroblast outgrowth. $J$ Cell Sci 123, 3336-3346

9. Hu, L., Roth, J. M., Brooks, P., Luty, J., and Karpatkin, S. (2008) Thrombin upregulates cathepsin $\mathrm{D}$ which enhances angiogenesis, growth, and metastasis. Cancer Res 68, 4666-4673

10. Glondu, M., Liaudet-Coopman, E., Derocq, D., Platet, N., Rochefort, H., and Garcia, M. (2002) Down-regulation of cathepsin-D expression by antisense gene transfer inhibits tumor growth and experimental lung metastasis of human breast cancer cells. Oncogene 21, 5127-5134

11. Hasilik, A., von Figura, K., Conzelmann, E., Nehrkorn, H., and Sandhoff, K. (1982) Lysosomal enzyme precursors in human fibroblasts. Activation of cathepsin D precursor in vitro and activity of beta-hexosaminidase $A$ precursor towards ganglioside GM2. Eur J Biochem 125, 317-321

12. Stubbs, M., McSheehy, P. M., Griffiths, J. R., and Bashford, C. L. (2000) Causes and consequences of tumour acidity and implications for treatment. Mol Med Today 6, 15-19

13. Schornack, P. A., and Gillies, R. J. (2003) Contributions of cell metabolism and $\mathrm{H}+$ diffusion to the acidic $\mathrm{pH}$ of tumors. Neoplasia 5, 135-145 
14. Griffiths, J. R., McIntyre, D. J., Howe, F. A., and Stubbs, M. (2001) Why are cancers acidic? A carrier-mediated diffusion model for $\mathrm{H}+$ transport in the interstitial fluid. Novartis Found Symp 240, 46-62; discussion 62-47, 152-153

15. Mohamed, M. M., and Sloane, B. F. (2006) Cysteine cathepsins: multifunctional enzymes in cancer. Nat Rev Cancer 6, 764-775

16. Wallin, H., Bjarnadottir, M., Vogel, L. K., Wasselius, J., Ekstrom, U., and Abrahamson, M. (2010) Cystatins--Extra- and intracellular cysteine protease inhibitors: High-level secretion and uptake of cystatin $C$ in human neuroblastoma cells. Biochimie 92, 1625-1634

17. Mason, S. D., and Joyce, J. A. (2011) Proteolytic networks in cancer. Trends Cell Biol 21, 228-237

18. Overall, C. M., and Dean, R. A. (2006) Degradomics: systems biology of the protease web. Pleiotropic roles of MMPs in cancer. Cancer Metastasis Rev 25, $69-75$

19. Kleifeld, O., Doucet, A., auf dem Keller, U., Prudova, A., Schilling, O., Kainthan, R. K., Starr, A. E., Foster, L. J., Kizhakkedathu, J. N., and Overall, C. M. (2010) Isotopic labeling of terminal amines in complex samples identifies protein $\mathrm{N}$-termini and protease cleavage products. Nat Biotechno/ 28, 281-288

20. Kleifeld, O., Doucet, A., Prudova, A., Auf dem Keller, U., Gioia, M., Kizhakkedathu, J. N., and Overall, C. M. (2011) Identifying and quantifying proteolytic events and the natural $\mathrm{N}$ terminome by terminal amine isotopic labeling of substrates. Nat Protoc 6, 1578-1611

21. Craig, R., and Beavis, R. C. (2004) TANDEM: matching proteins with tandem mass spectra. Bioinformatics 20, 1466-1467 
22. auf dem Keller, U., Prudova, A., Gioia, M., Butler, G. S., and Overall, C. M. (2010) A statistics-based platform for quantitative N-terminome analysis and identification of protease cleavage products. Mol Cell Proteomics 9, 912-927

23. Watabe, S., and Yago, N. (1983) Phospholipids activate cathepsin D. Biochem Biophys Res Commun 110, 934-939

24. Tholen, S., Biniossek, M. L., Gessler, A. L., Muller, S., Weisser, J., Kizhakkedathu, J. N., Reinheckel, T., and Schilling, O. (2011) Contribution of cathepsin $\mathrm{L}$ to secretome composition and cleavage pattern of mouse embryonic fibroblasts. Biol Chem 392, 961-971

25. Lenarcic, B., Krasovec, M., Ritonja, A., Olafsson, I., and Turk, V. (1991) Inactivation of human cystatin $\mathrm{C}$ and kininogen by human cathepsin D. FEBS Lett 280, 211-215

26. Kopitz, C., Anton, M., Gansbacher, B., and Kruger, A. (2005) Reduction of experimental human fibrosarcoma lung metastasis in mice by adenovirusmediated cystatin C overexpression in the host. Cancer Res 65, 8608-8612

27. Huh, C. G., Hakansson, K., Nathanson, C. M., Thorgeirsson, U. P., Jonsson, N., Grubb, A., Abrahamson, M., and Karlsson, S. (1999) Decreased metastatic spread in mice homozygous for a null allele of the cystatin C protease inhibitor gene. Mol Pathol 52, 332-340

28. Wegiel, B., Jiborn, T., Abrahamson, M., Helczynski, L., Otterbein, L., Persson, J. L., and Bjartell, A. (2009) Cystatin C is downregulated in prostate cancer and modulates invasion of prostate cancer cells via MAPK/Erk and androgen receptor pathways. PLoS One 4, e7953

29. Bell-McGuinn, K. M., Garfall, A. L., Bogyo, M., Hanahan, D., and Joyce, J. A. (2007) Inhibition of cysteine cathepsin protease activity enhances 
chemotherapy regimens by decreasing tumor growth and invasiveness in a mouse model of multistage cancer. Cancer Res 67, 7378-7385

30. Abboud-Jarrous, G., Atzmon, R., Peretz, T., Palermo, C., Gadea, B. B., Joyce, J. A., and Vlodavsky, I. (2008) Cathepsin $L$ is responsible for processing and activation of proheparanase through multiple cleavages of a linker segment. $J$ Biol Chem 283, 18167-18176

31. Turk, B. (2006) Targeting proteases: successes, failures and future prospects. Nat Rev Drug Discov 5, 785-799

32. Turk, V., Kos, J., and Turk, B. (2004) Cysteine cathepsins (proteases)--on the main stage of cancer? Cancer Cell 5, 409-410

33. Dean, R. A., and Overall, C. M. (2007) Proteomics discovery of metalloproteinase substrates in the cellular context by iTRAQ labeling reveals a diverse MMP-2 substrate degradome. Mol Cell Proteomics 6, 611-623

34. Derocq, D., Prebois, C., Beaujouin, M., Laurent-Matha, V., Pattingre, S., Smith, G. K., and Liaudet-Coopman, E. (2011) Cathepsin D is partly endocytosed by the LRP1 receptor and inhibits LRP1-regulated intramembrane proteolysis. Oncogene

35. Laurent-Matha, V., Lucas, A., Huttler, S., Sandhoff, K., Garcia, M., and Rochefort, H. (2002) Procathepsin D interacts with prosaposin in cancer cells but its internalization is not mediated by LDL receptor-related protein. Exp Cell Res 277, 210-219

36. Dean, R. A., Butler, G. S., Hamma-Kourbali, Y., Delbe, J., Brigstock, D. R., Courty, J., and Overall, C. M. (2007) Identification of candidate angiogenic inhibitors processed by matrix metalloproteinase 2 (MMP-2) in cell-based proteomic screens: disruption of vascular endothelial growth factor 
(VEGF)/heparin affin regulatory peptide (pleiotrophin) and VEGF/Connective tissue growth factor angiogenic inhibitory complexes by MMP-2 proteolysis. Mol Cell Biol 27, 8454-8465

37. Dunn, B. M., and Hung, S. (2000) The two sides of enzyme-substrate specificity: lessons from the aspartic proteinases. Biochim Biophys Acta 1477, $231-240$

38. Lenarcic, B., Kos, J., Dolenc, I., Lucovnik, P., Krizaj, I., and Turk, V. (1988) Cathepsin D inactivates cysteine proteinase inhibitors, cystatins. Biochem Biophys Res Commun 154, 765-772

39. Griffiths, J. R. (1991) Are cancer cells acidic? Br J Cancer 64, 425-427

40. Martino, S., Tiribuzi, R., Ciraci, E., Makrypidi, G., D'Angelo, F., di Girolamo, I., Gritti, A., de Angelis, G. M., Papaccio, G., Sampaolesi, M., Berardi, A. C., Datti, A., and Orlacchio, A. (2011) Coordinated involvement of cathepsins S, D and cystatin $C$ in the commitment of hematopoietic stem cells to dendritic cells. Int J Biochem Cell Biol 43, 775-783

41. van der Stappen, J. W., Williams, A. C., Maciewicz, R. A., and Paraskeva, C. (1996) Activation of cathepsin B, secreted by a colorectal cancer cell line requires low $\mathrm{pH}$ and is mediated by cathepsin $\mathrm{D}$. Int $J$ Cancer $67,547-554$

42. Gillet, L., Roger, S., Besson, P., Lecaille, F., Gore, J., Bougnoux, P., Lalmanach, G., and Le Guennec, J. Y. (2009) Voltage-gated Sodium Channel Activity Promotes Cysteine Cathepsin-dependent Invasiveness and Colony Growth of Human Cancer Cells. J Biol Chem 284, 8680-8691

43. Jelassi, B., Chantome, A., Alcaraz-Perez, F., Baroja-Mazo, A., Cayuela, M. L., Pelegrin, P., Surprenant, A., and Roger, S. (2011) P2X(7) receptor activation 
enhances SK3 channels- and cystein cathepsin-dependent cancer cells invasiveness. Oncogene 30, 2108-2122

44. Brisson, L., Gillet, L., Calaghan, S., Besson, P., Le Guennec, J. Y., Roger, S., and Gore, J. (2011) $\mathrm{Na}(\mathrm{V}) 1.5$ enhances breast cancer cell invasiveness by increasing NHE1-dependent $\mathrm{H}(+)$ efflux in caveolae. Oncogene 30, 2070-2076

\section{FIGURE LEGENDS}

Figure 1. Binding of cystatin $C$ to procathepsin $D$ secreted by breast cancer cells at neutral $\mathrm{pH}$

(A) Sequence of cystatin C interacting with procathepsin D. Human cystatin C is synthesized as a 146-amino-acid protein. The signal peptide (residues 1-26) is shown in italic. Residues 39-146, isolated by the yeast two-hybrid method, are underlined.

(B) Binding of procathepsin D to cystatin C by GST pull-down. Radio-labeled human procathepsin $D$ synthesized in the reticulocyte lysate system was incubated with glutathione-Sepharose beads containing GST-cystatin C (GST-Cyst C) or GST alone. GST proteins were stained with Coomassie (panel a), and bound procathepsin D was detected by autoradiography (panel b). The input corresponds to the lysate used for the binding reaction.

(C) Extracellular interaction of transfected procathepsin D and cystatin C. COS cells were transiently co-transfected with the expression vectors for human cystatin C and cathepsin D and the conditioned medium was obtained $48 \mathrm{~h}$ post-transfection. Panel a: the conditioned medium was immunoprecipitated with anti-cathepsin D M1G8 monoclonal, anti-cystatin C rabbit polyclonal, and control rabbit polyclonal 
(IgG) antibodies. Panel b: immunoprecipitations with anti-cathepsin D M1G8 monoclonal, anti-cystatin C polyclonal, and MOPC monoclonal antibodies. Conditioned medium (CM) $(100 \mu \mathrm{l})$, and cathepsin D, cystatin C and control (IgG or MOPC) immunoprecipitates (IP) were analyzed by anti-cathepsin D (panel a) and anti-cystatin C (panel b) immunoblotting. Arrows show co-immunoprecipitates of procathepsin D and cystatin C.

(D) Co-purification of secreted procathepsin D and cystatin C. Cystatin C was co-purified with procathepsin $D$ in the extracellular culture medium of cathepsin Dtransfected NIH-3T3 fibroblasts (panel a) and in MCF-7 cells (panel b). Cells grown to $90 \%$ confluence were incubated for $24 \mathrm{~h}$ in serum-free medium and this conditioned medium was loaded onto an anti-cathepsin D M1G8 affinity column. The eluted fraction (EF) corresponding to $2 \mu \mathrm{g}$ of purified procathepsin $\mathrm{D}$ and conditioned medium were analysed by anti-cystatin $\mathrm{C}$ immunoblotting. Arrows show cystatin $\mathrm{C}$ co-purified with procathepsin D. Cystatin C secretion was analysed in the conditioned media of cancer cells maintained in DMEM with $10 \%$ FCS for $24 \mathrm{~h}$ by anti-cystatin C immunoblotting (panel c). NS, non-specific band showing sample loading.

\section{Figure 2. Cystatin analysis in cath- $D^{-/-}$MEFs transfected with cathepsin $D$}

\section{(A) Identification of protein termini affected by cathepsin D deficiency by TAILS}

Comparison of the amounts of identified protein $\mathrm{N}$-termini in the secretomes of cathepsin D deficient murine cells expressing human cathepsin $D$ (CD55-/-cath-D) and of cells transfected with empty vector (control, CD55-/-SV40) is presented. The distribution of the ratios of cathepsin D expressing cells versus control (log2) among the identified $\mathrm{N}$-termini in secretomes is shown. Protein termini whose amount changed more than 3-fold (log2 above 1.58 or below -1.58 , highlighted in light grey) 
were considered severely affected. An arrow indicates the bin in which the mature Nterminus of murine cystatin $\mathrm{C}$ was found.

(B) Identification of mRNAs affected by cathepsin $D$ deficiency by transcriptomic analysis

Distribution of the expression values (in log2 of ratio) between CD55-/-cath-D and CD55-/-SV40 as boxplot, one for each replicate is shown. Expression values for cystatin C are represented by a diamond (values of 1.51 and 1.42), respectively. Conventional threshold (Fold-change $>=2$ or $\langle=-2$, i.e $\log 2(\mathrm{R})>=1$ or $<=-1$ ) was used to consider a gene as over- (respectively under-) expressed is shown as dashed line.

Figure 3. Cleavage of cystatin $\mathrm{C}$ by $52-\mathrm{kDa}$ procathepsin $\mathrm{D}$ auto-activated to proteolytically-active 51-kDa enzyme at acidic pH

Panel a: recombinant $52-\mathrm{kDa}$ procathepsin $\mathrm{D}$ was auto-activated to proteolyticallyactive $51-\mathrm{kDa}$ cathepsin $\mathrm{D}$ by incubation at $\mathrm{pH} 3.5$ for $1 \mathrm{~h}$. It was then incubated with recombinant cystatin $\mathrm{C}$ at $\mathrm{pH} 3.5$ with or without pepstatin $\mathrm{A}$. Panel b: sites of cystatin C cleavage by proteolytically-active $51-\mathrm{kDa}$ cathepsin $\mathrm{D}$ at low $\mathrm{pH}$. Cleaved cystatin C peptides were separated by reverse-phase HPLC and subjected to NH2-terminal sequence analysis. $(\rightarrow)$, major sites cleaved by $51-k D a$ cathepsin $\mathrm{D} ;(->)$, minor sites cleaved by $51-\mathrm{kDa}$ cathepsin $\mathrm{D}$; *, published cleavage sites of $34+14-\mathrm{kDa}$ mature cathepsin D (25).

Figure 4. Degradation of cystatin C by procathepsin D secreted by breast cancer cells at acidic $\mathrm{pH}$ 
(A) Time-course of cystatin C degradation in MCF-7 cells. Cells were incubated for $24 \mathrm{~h}$ in FCS-free DMEM without sodium bicarbonate buffered with $50 \mathrm{mM}$ Hepes, $\mathrm{pH}$ 7. The $24 \mathrm{~h}$ conditioned medium was then incubated, with or without pepstatin $\mathrm{A}$ $(50 \mu \mathrm{M})$, at $37^{\circ} \mathrm{C}$ at $\mathrm{pH} 3.5$ by acidification with $1 \mathrm{~N} \mathrm{HCl}$, for up to $180 \mathrm{~min}$. Conditioned medium was analysed by anti-cathepsin D and anti-cystatin C immunoblotting. Panel a: 52-kDa procathepsin D auto-activated to $51-\mathrm{kDa}$ cathepsin $\mathrm{D}$ in the acidic conditioned medium at $30 \mathrm{~min}$ in the absence of pepstatin A. Panel b: breakdown of cystatin $C$ in the absence of pepstatin $A$.

(B) Influence of acidity on cystatin C degradation in MCF-7 cells. Cells were incubated for $24 \mathrm{~h}$ in DMEM without sodium bicarbonate buffered with $50 \mathrm{mM}$ Hepes, $\mathrm{pH}$ 7. The conditioned medium was then incubated at the indicated $\mathrm{pH}$ using BrittonRobinson buffer for $1 \mathrm{~h}$ with or without pepstatin $\mathrm{A}(50 \mu \mathrm{M})$. Panel a: conditioned medium subjected to SDS-PAGE and anti-cystatin C immunoblotting. Panel b: mean \pm SD (3 independent experiments). $\mathrm{P}<0.05$ versus cystatin level in presence of pepstatin A for each $\mathrm{pH}$ (Student's $t$-test).

(C) Hydrolysis of cystatin C by procathepsin D secreted by MCF-7 cells. MCF-7 cells were transfected with Luc or cathepsin D siRNAs. 48 h-post-transfection, the culture medium was changed and conditioned media were prepared by incubating the siRNA-transfected cells in FCS-free DMEM without sodium bicarbonate buffered with $50 \mathrm{mM}$ Hepes $\mathrm{pH} 7$ for $24 \mathrm{~h}$. Panels a and c: the procathepsin D and cystatin C secreted into the conditioned medium of cells transfected with Luc or cathepsin D siRNAs assessed by immunoblotting. Panel b: the conditioned media of cells transfected with Luc or cathepsin D siRNAs were then incubated at $\mathrm{pH} 3.5$ for the indicated times with or without pepstatin A, and analysed by SDS-PAGE and anticystatin C immunoblotting. Panel d: the conditioned media of cells transfected with 
Luc or cathepsin D siRNAs were then incubated at $\mathrm{pH} 5.6$ for $2 \mathrm{~h}$ with or without pepstatin $A$, and analysed as in panel b.

Figure 5. Cystatin C degradation by procathepsin D led to increased proteolytic activity of the extracellular cysteine cathepsins in breast cancer cells at pH 3.5 MCF-7 cells were transfected with Luc or cathepsin D siRNAs. 48 h-post-transfection, DMEM medium without sodium bicarbonate buffered with $50 \mathrm{mM}$ Hepes $(\mathrm{pH} 7)$ was added and the cells were incubated for a further $24 \mathrm{~h}$ in the absence of serum. Panel a: the procathepsin $D$ and cystatin $C$ secreted into the conditioned medium of cells transfected with Luc or cathepsin D siRNAs assessed by immunoblotting. Panel b: the conditioned media obtained from the siRNA-transfected cells secreting procathepsin D and Luc controls were incubated at $\mathrm{pH} 3.5$ for 10 min with or without pepstatin $A(50 \mu \mathrm{M})$. The cystatin $\mathrm{C}$ in the four corresponding conditioned media was analysed by SDS-PAGE and anti-cystatin C immunoblotting (lanes 1-4). Panel c: cysteine cathepsin proteolytic activity in the four conditioned media (lanes 1-4) (quadruplicate analysis). Means $\pm \mathrm{SD}$ are shown. $\mathrm{P}<0.005$ versus lane 1 (Student's $t$ test).

Figure 6. Cystatin C degradation led to increased proteolytic activity of the extracellular cysteine cathepsins in breast cancer cells at pH 5.6

Panel a: the conditioned medium obtained from MCF-7 cells was incubated at $\mathrm{pH} 5.6$ for 1 or $2 \mathrm{~h}$ with or without pepstatin $\mathrm{A}(50 \mu \mathrm{M})$. The cystatin $\mathrm{C}$ in the four corresponding conditioned media was analysed by SDS-PAGE and anti-cystatin C immunoblotting. Panel b: cysteine cathepsin proteolytic activity in the four corresponding conditioned media. Mean values \pm SD from 6 measurements are 
shown. $\mathrm{P}<0.005$ versus cysteine cathepsin proteolytic activity at $1 \mathrm{~h}$ in absence of pepstatin A (Student's t-test). Panel c: Detection of cathepsins B, H, L, K and S in the conditioned medium (CM) of MCF-7 cells by immunoblotting. Mature cathepsins $\mathrm{B}, \mathrm{H}$, $\mathrm{L}, \mathrm{K}$ and $\mathrm{S}$ were used as control. *, proform; < mature form.

Figure 7. Model of cystatin C inactivation by procathepsin D in the tumor microenvironment of cancers cells

We propose that procathepsin $\mathrm{D}$ secreted in excess by cancer cells degrades cystatin C, thereby leading to an increased extracellular proteolytic activity of cysteine cathepsins, such as cathepsin B in particular. The procathepsin D secreted by breast cancer cells is therefore a new component of tumor progression that triggers the proteolytic networks by inactivating cystatin C. 